\title{
An Approach to Combine an Independent Metering System with an Electro-Hydraulic Flow-on-Demand Hybrid-System
}

\author{
M. WYDRA, M. GEIMER, and B. WEISS* \\ Karlsruhe Institute of Technology, Chair of Mobile Machines, Karlsruhe, Germany \\ E-mail: marco.wydra@kit.edu, marcus.geimer@kit.edu,bweiss@weiss-can-sps.de \\ *Weiss Mobiltechnik GmbH, Rohrdorf, Germany
}

\begin{abstract}
By combining an electro-hydraulic flow-on-demand system with an independent metering of the actuators in- and outlet, a higher efficiency and a better controllability compared to conventional hydraulic-mechanic load sensing systems can be reached. It also enables the integration of a hydraulic accumulator to recuperate energy due to active loads. This paper presents an alternative control strategy for this kind of hydraulic propulsion systems. Connected with the pump and during passive loads the meter-in flow controls the velocity of the actuator. Otherwise the velocity control is achieved by the meter-out flow while the oil flows into the accumulator or tank. Exemplary this system is simulated for a mobile forestry crane. Further steps are building up a test bench for optimization and validation as well as an implementation into a real machine for testing the suitability in use.
\end{abstract}

Keywords: flow-on-demand, independent metering, control, recuperation, hybrid system

\section{Introduction}

With the investigation of electronic components the automation of processes gets more important. This means that in times of Industry 4.0, machines are fully integrated with sensors to observe the current status. In mobile machines this leads to change the current manual hydraulic-mechanic actuation to automated electro-hydraulic actuation. A first step is to change the hydraulic-mechanic components of the hydraulic system with obtainable electric-hydraulic components. Hereby the possibility to improve the efficiency of mobile machines is increased. [1]

For this, Scherer presents in [2] an electro-hydraulic flowon-demand system (eBSS) which needs an electric actuated pump and valves. eBSS may reduces the used energy of the pump up to $10-12 \%$ depending on the application and the load cycle of the machine. This is caused by the reduction of pressure losses between system pressure and load sensing (LS) pressure from usually 10-30 bar in LS-systems [3] to 810 bar in eBSS-systems, cf. fig. 1 diagram (I) \& (II). In LSsystems the LS-pressure losses can also be reduced by pump pressure settings, but this influences the dynamic behaviour of the system [2].

Actuating the pump and the valves simultaneously by the same control signal, such control is more immediately and comfortable [2].

Due to the electro-hydraulic actuation of the valves, the consecutive step is to separate the meter-in and meter-out control edge, which is well researched by [4], [5], [6].
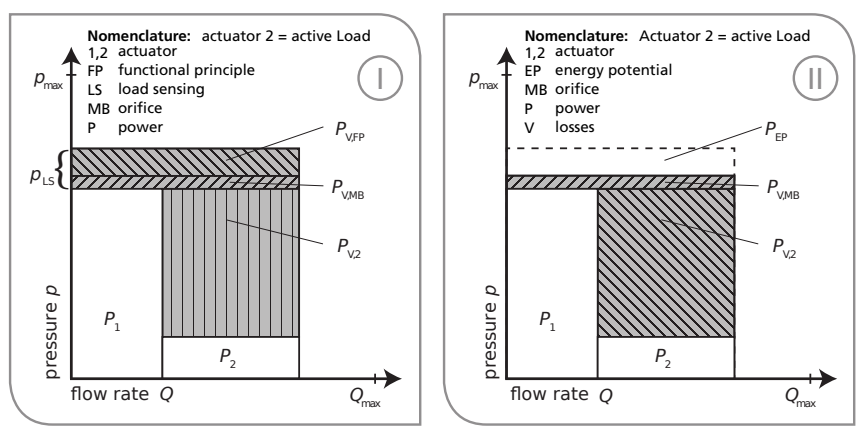

Figure 1: Pump performance for several systems: (I) LS-system, (II) eBSS-system [2]

Especially Axin declares in [4] different kinds of operating modes called normal operation mode, regenerative operation mode, energy neutral operation mode and recuperative operation mode. These new modes can reduce the needed pump performance as shown in the diagrams (III) \& (IV) in fig. 2.

Based on the proposed systems, this paper will show a control strategy using the electro-hydraulic flow-on-demand by separating the actuators meter-in and meter-out control edges and implementing a hydraulic accumulator due to the possible operating modes. 

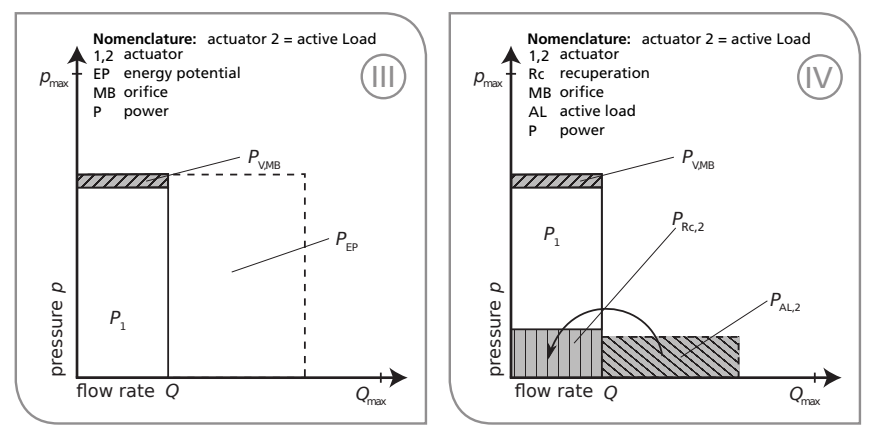

Figure 2: Pump performance for several systems:

(III) eBSS+IM-system, (IV) eBSS+IM-system with hybridization [2]

\subsection{Operation Modes}

By using independent metering, it is possible to choose between several operation modes. To classify these operation modes, it is necessary to monitor the actuators status and match it with the possibilities to connect the actuators in- and outlet with the pump, tank or accumulator.

The actuators status is defined by its movement and the resulting forces due to the loads, friction and pressure, see fig 3. The resulting force $F_{\text {Load }}$ to an actuator is defined in equation (1). For the following explanations, a differential-cylinder is used as an exemplary actuator.

$$
F_{\text {Load }}=p_{B} \cdot A_{B}-p_{A} \cdot A_{A}+F_{\text {Fric }}
$$
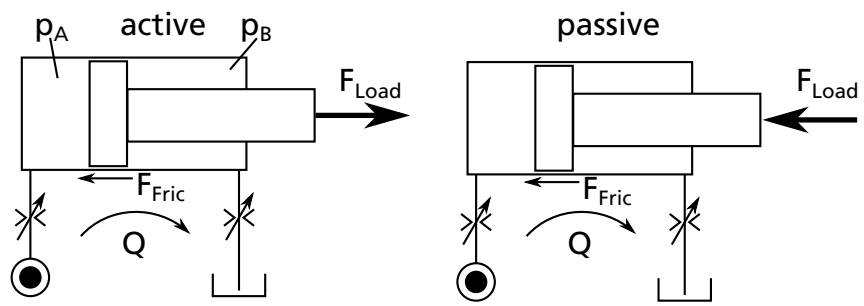

Figure 3: Active and passive loads

When both, the motion and load force vector have the same direction, the status is called active load, otherwise it is a passive load. In passive load situations, an actuator is always moved by the flow rate of the pump. In this paper, the actuators movement is referred to as the movement demanded by an operator. The decisions in the controller design will be independent of the measured actuator velocity.

Separating the meter-in and meter-out control edge gives the possibility to connect the actuator as shown in fig. 4. In normal operation mode (NOM), the inlet is connected to the pump, the outlet to the tank. With an independent metering it is possible to optimize the meter-out control edge throttle losses [4]. Furthermore, the regulation of the meter-out control edge influences the pressure in the inlet chamber. With a pressure control of the inlet chamber, the system can be forced to be in passive load status. Therefore, cavitation in the inlet chamber can be minimized. The velocity of the actuator is adjusted by the meter-in control edge. The same functionality is offered by a lowering brake valve.
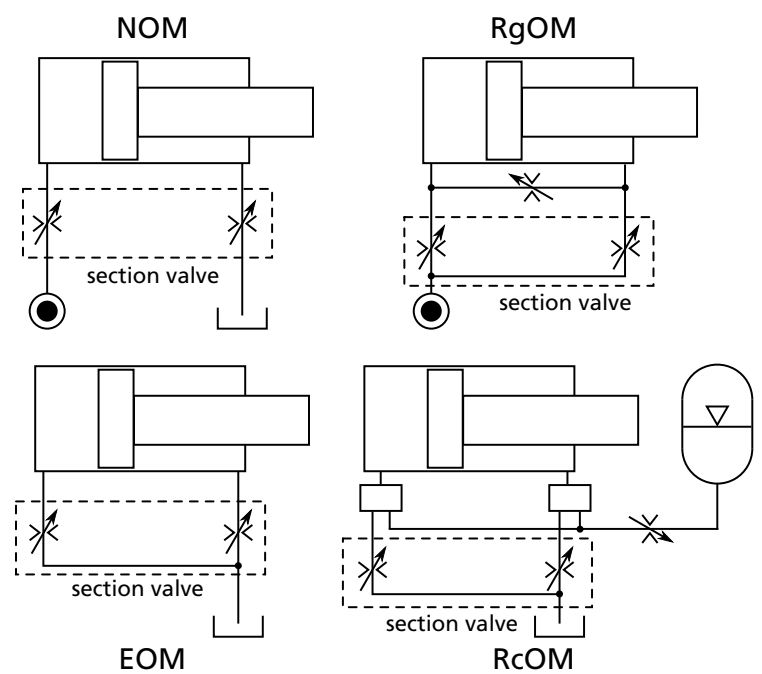

Figure 4: Possibilities to connect an actuator with separate control edges; NOM - normal operation mode, EOM - energy neutral operation mode, $\mathrm{RgOM}$ - regenerative operation mode, RcOM - recuperative operation mode

Connecting the pump with the in- and outlet of the actuator, the operation mode is called regenerative operation mode $(\mathrm{RgOM}) . \mathrm{RgOM}$ can reduce throttle losses in hydraulic systems with great pressure differences between the various actuators [4]. This is caused by increasing pressure due to a smaller operation area. The oil supply by the pump is reduced in amount of the out-flowing oil, see equation (3). In this paper the $\mathrm{RgOM}$ is neglected, because it will increase the complexity and the number of necessary components.

$$
\begin{aligned}
Q_{\text {Pump }, \text { NOM }} & =Q_{\text {In }} \\
Q_{\text {Pump }, \text { RgOM }} & =Q_{\text {In }}-Q_{\text {Out }}
\end{aligned}
$$

The energy neutral operation mode (EOM) is a special part of regeneration. Here the actuators chambers are connected to the tank, so the flow rate to the inlet is the sum of the outflowing oil and, if necessary, oil from the tank, see equation 5. No oil from the pump is needed here. This reduces the throttle losses as well as the demanded power by the primary energy supply and in addition influences the oil temperature. Here, the meter-out orifice adjusts the actuator's velocity. [4]

$$
Q_{\text {Pump }, E O M / R c O M}=0
$$

because of

$$
Q_{\text {In }}=Q_{\text {out }}\left(+Q_{\text {Tank }}\right)
$$

The last operation mode is the recuperative operation mode ( $\mathrm{RcOM})$. This mode is very close to the EOM. Instead of 
connecting the outlet with the tank, it is connected to the accumulator [4]. Therefore, a reduction of pressure losses will be achieved by a smaller pressure difference between the actuator's outlet pressure $p_{\text {Out }}$ and the rising accumulator pressure $p_{\text {Acc }}$, see figure 5. Like in EOM, the meter-out orifice is used to control the actuator's velocity. This operation mode will be preferred by active loads and swaps with the EOM during operation.

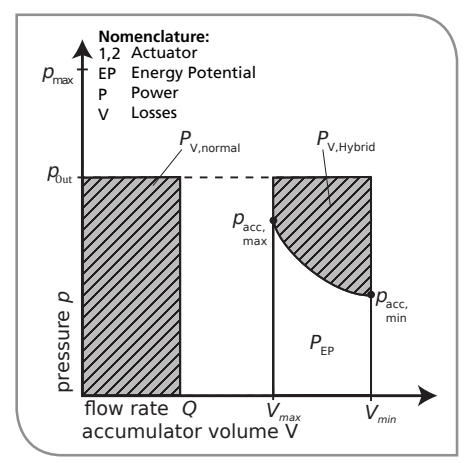

Figure 5: Throttle losses for active loads: relaxing to tank(left) and to accumulator(right); throttle losses to accumulator depends on $p_{a c c}$

The way of using the RcOM strongly depends on the given load situations and the operations strategy. In this paper, the authors primarily focuses on buffering energy into the accumulator. The buffered energy will not be used in a specific way. More information and possibilities to use the recuperative potential can be found in [7] or [8].

The accumulator can also be used to reduce the throttling losses at the section valves during the NOM. Siebert wrote about this possibility in [9]. The current paper focuses on the filling of the accumulator without evoking a unsuitable operation behaviour for the operator.

\section{Application to a Mobile Forestry Crane}

Within a public funded research project at the Karlsruhe Institute of Technology (KIT), the following controller design will be tested on a mobile forestry crane like in [2] with the eBSS system before. First of all it is tested in a simulation, then on a test bench and finally the system will be integrated in a demonstrator. For that, the following lines show the system structure and the provided controller design.

\subsection{System Structure}

The electro-hydraulic flow-on-demand system integrates a load independence due to individual secondary pressure compensator [2]. The system is a flow-sharing system, which means during a higher demand of flow rate than the maximum flow rate of the pump, all actuators will operate with a reduced velocity. The displacement of the pump is adjusted by an electro-hydraulic controller which controls the delay angle of the swash plate [2]. The pump controller is overlain by a pressure control valve which regulates the maximum pressure of the hydraulic system, cf. fig. 6 .
The position of the section valve spool is forced by the control-signal $u$. For this, the section valves are equipped with an internal position control of the spool. Thus, it is possible to match the actuators flow rate via the section valves to the current displacement of the pump.

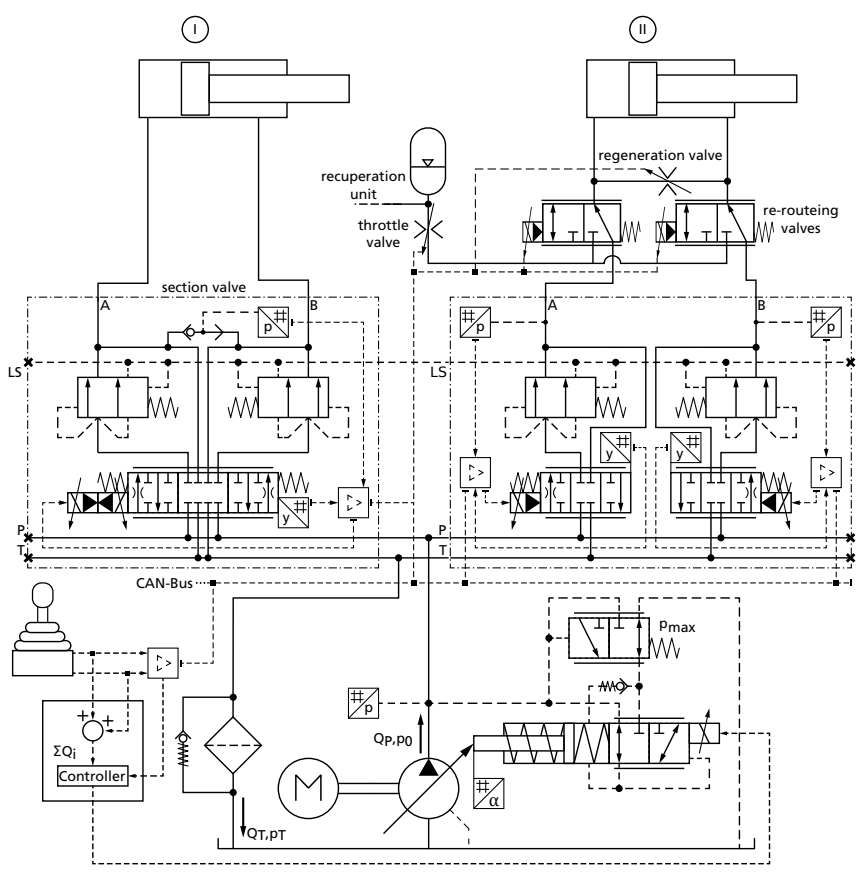

Figure 6: eBSS-system with conventional valve (I) and with separated control edges (II)

For each section, the current $8 / 4$-valve will be replaced by two 4/3-valves, so the in- and outlet of an actuator can be controlled independently. Figure 6 shows a hydraulic circuit with two actuators including all needed components for all possible modes. While actuator one (left-handed) is equipped with the conventional section valve, the second actuator is equipped with the new section valve. Each valve possess a secondary pressure compensator.

As mentioned in 1.1, the regenerative operation mode $(\mathrm{RgOM})$ could only be realized in this system by adding a valve from the outlet to the inlet between the actuator and the section valves, cf. fig. 6. This is necessary to omit the secondary pressure compensator and allow a flow rate from the inlet to the outlet. For now, this mode is not considered.

To include the hybrid system in the hydraulic circuit and thus the recuperative operation mode ( $\mathrm{RcOM})$, it is necessary to reroute the out flowing oil. This will be done by a 3/2-valve in each line of the actuator, cf. re-routeing valve in fig. 6. In several modes, those valves can redirect the oil to the accumulator. Depending on the operation strategy, it is possible to use only one or more accumulators in the system. For this choice, e.g. the actuators pressure level will be one criterion.

To control the actuators velocity, it is also necessary to implement a flow rate controlling component to the accumulator. In this paper, it is represented by an orifice (throttle valve), cf. fig. 6 . To reduce the needed pressure difference compared to regular flow-control valves, this element will be realized by a 
proportional throttle valve, where the flow rate is controlled by eq. (7).

This bases on the formula for orifices after Bernoulli, eq. (6) [10]. $\alpha_{D}$ is the flow coefficient and $\rho$ is the density of the oil. Both are assumed to be constant for this controller design. Therefore, $K$ is a composition of all constant values in eq. (6). The actuator's out-coming flow rate $Q_{\text {out }}$,ref is equal to the flow rate to the accumulator $Q_{A c c}$. So the spools position $y$ will be controlled in dependency of $Q_{A c c}$ and the difference between the actuator's outlet pressure $p_{\text {Out }}$ and the accumulator pressure $p_{A c c}$. Several researches have been done on this topic by [11] and [12].

$$
\begin{array}{r}
Q=\alpha_{D} \cdot \sqrt{\frac{2}{\rho}} \cdot A(y) \cdot \sqrt{\Delta p} \\
Q_{A c c}=Q_{\text {Out }, \text { ref }}=K \cdot y \cdot \sqrt{p_{\text {Out }}-p_{A c c}}
\end{array}
$$

A similar control strategy will also be used to control the flow rate to the tank. This will be discussed in detail in the next section.

\subsection{Controller Design}

The primary task of this controller design is to decide which operation mode $(\mathrm{OM})$ is temporarily the best for energy saving and safety. The RcOM is the most energy efficient but also, because of its conditions, the most unstable OM. The next efficient mode in this ranking is the EOM, because no primary energy is used, but the throttle losses are higher than in RcOM. The NOM has no efficiency advantages compared to a conventional LS-system. However, NOM is the most stable OM compared to EOM and RcOM. Therefore, it is used as the fall-back OM in critical situations.

To choose the right $\mathrm{OM}$, the controller combines the operator's requested movement, detected by the joystick-signal $u_{\text {Joy }}$, and the actuator's outlet pressure $p_{\text {Out }}$ as well as the accumulator pressure $p_{A c c}$, cf. fig. 7. In parallel, the controller calculates (calculator block) different control-signals for each OM, depending on the current system status. A simple boolean algebra (mode switch) then decides which controlsignals $\left(u_{\text {In }}, u_{\text {Out }}\right)$ are released to the adjusted section valves, cf. fig. 7. The valve to control the inlet flow depends on the actuators movement. Figure 7 shows exemplary the signal routing for the extension of the cylinder.

The mode switch consists of several decisions. The sequence for these is shown for a predefined situation in fig. 8. A grey cylinder chamber implies high pressure. At first the controller design has to check the moving direction due to $u_{J o y}$. This leads to the information which chamber is the outlet of the actuator and so it is possible to allocate the calculated controlsignals to the specific valve.

The next important information is to know the value of $p_{\text {Out }}$. The controller design assumes for a closed section valve, that an active load situation is represented by an high pressure at the actuator's outlet. If the value of $p_{O u t}$ is higher than the upper limit $p_{E O M, o n}$, the controller design will activate the EOM.

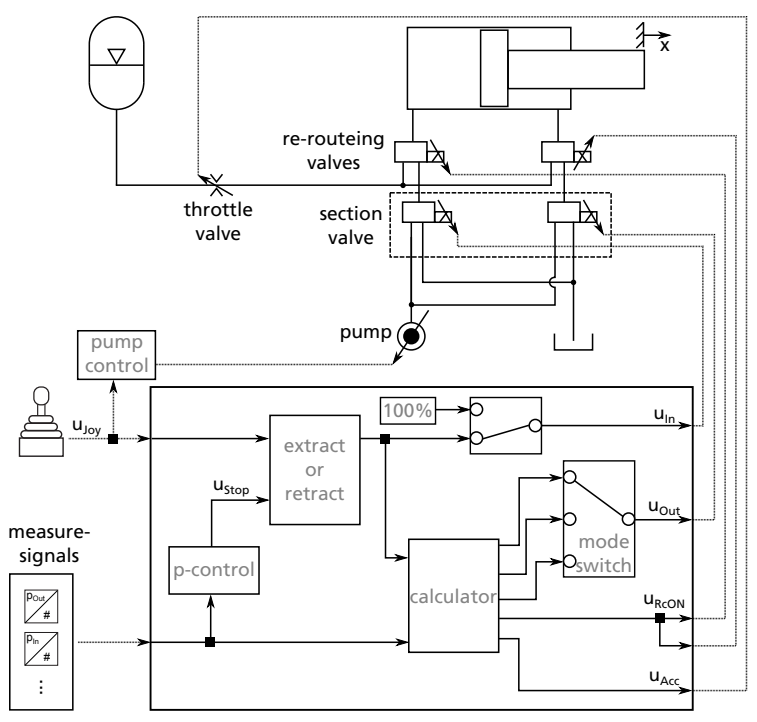

Figure 7: Scheme of the controller design

Using only the independent metering without the hybrid system, the mode switch of the controller design is complete and does not need any other conditions.

To include the RcOM, there are more selections needed, cf. fig. 8. To swap between EOM and RcOM the controller design has to check if $p_{\text {Out }}$ is able to transport oil into the accumulator. For this, the condition in eq. (8) has to be fulfilled [13].

$$
p_{\text {Out }}-p_{\text {Acc }}>\Delta p_{\text {Losses }}+\Delta p_{\text {RcOM,on }}
$$

The left part of the equation is the maximum pressure difference possible to force oil to the accumulator. The right part consists of the current pressure losses $\Delta p_{\text {Losses }}$ in the piping from the outlet to the accumulator plus the upper switching condition $\Delta p_{R c O M}$, on. $\Delta p_{\text {Losses }}$ variates with the flow rate and the operation of the throttle valve to the accumulator. The throttle valve losses can be calculated by eq. (6).

\begin{tabular}{|l|l|l|}
\hline status & information \\
\hline example status & check $\mathrm{u}_{\text {Joy }}$ &
\end{tabular}

Figure 8: Selection sequence of the mode switch block 
Working with discrete OMs has the disadvantage of periodical switching between different OMs. This can influence the system's stability and its suitability in use badly. Like in a twopoint switch, there is a higher and a lower switching condition to minimize the frequency of such situations. The function of the two-point switch is shown in fig. 9. If the new OM is selected at time $t_{1}$, a PI-controller will align the control-signal of the current OM into line with the control-signal $u_{\text {In } / \text { Out }}$ of the new OM. In fig. 9 the control-signal changes from NOM to EOM. On account on that, the control-signal is a steady function. All these features have influences on the dynamic behaviour of the system and have to be adapted for a performance accepted by the operator.

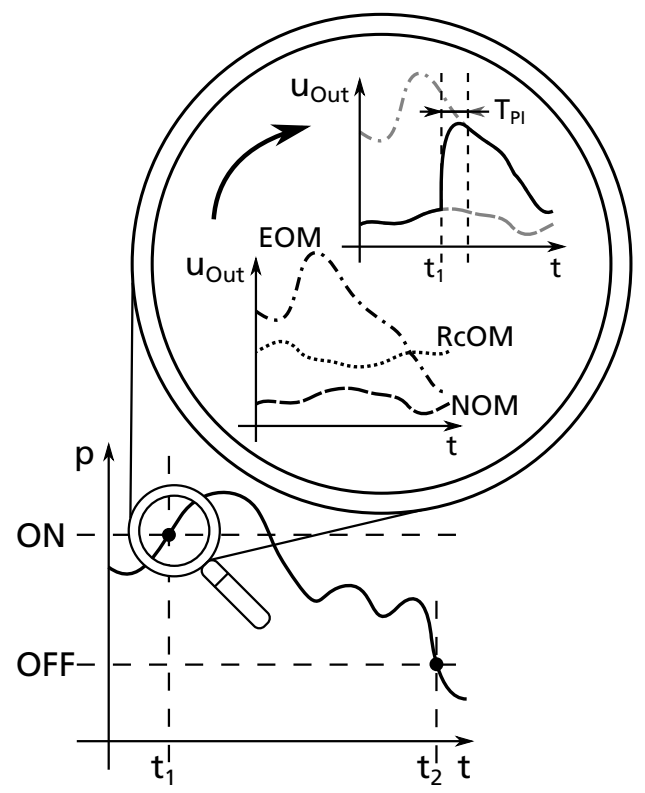

Figure 9: Representation of the two-point switch behaviour of the mode switch and the matching of the control-signals

Another problem shown in [2] is the behaviour of the controller, when an actuator drives against obstacles or reaches its end stop. At that moment, no oil flows to this actuator, but the operation signal would still adjust the pump. An increasing velocity of the active actuators is the result of this effect, while simultaneously the system pressure raises to its maximum. A maximum system pressure closes all individual secondary pressure compensator, so all other active actuators will stop afterwards. [2]

To avoid this, Scherer overlays the operation signal with an individual section pressure-control, which reduces the demand of oil for the regarded actuator [2]. The same safety mechanism will be used in this controller design.

\subsubsection{Calculating the Control-Signals}

According to [4], the current implemented controller design considers the normal operation mode (NOM), energy neutral operation mode (EOM) and recuperative operation mode (RcOM). The operator controls the inlet flow rate $Q_{I n, r e f}$ with an operation signal $u_{J o y}$ via an operator specified look-up table. This leads to the option making the controller design more aggressive or soft. By using the look-up table, the theoretical outlet flow $Q_{\text {Out,ref }}$ is predicted in eq. (9). $\alpha$ is the surface ratio of a differential cylinder. For actuators without a transforming property, the surface ratio $\alpha$ is equal to 1 .

$$
\begin{aligned}
Q_{\text {In }, \text { ref }} & =f\left(u_{\text {Joy }}\right) \\
Q_{\text {Out }, \text { ref }} & =\alpha \cdot Q_{\text {In }, \text { ref }}, \text { with } \alpha=\frac{A_{\text {Out }}}{A_{\text {In }}}
\end{aligned}
$$

During the NOM, the control-signal $u_{I n}$ for the inlet chamber is directly controlled by $u_{J o y}$. The actuator is connected to the pump and the secondary pressure compensator. This ensures a load independent flow rate. The position of the outlet valve spool $y_{\text {Out }}$ is calculated with eq. (11). $\Delta p$ is the difference between the actuators pressure in the outlet chamber $p_{\text {Out }}$ and the pressure of the tank $p_{T}$. No other influences are considered. The control edges flow surface $A_{C E, \text { Out }}$ is estimated according to equation (10). $A_{C E, \text { Out }}$ can also be represented by a look-up table to consider the proper geometry.

To avoid failure calculations because of complex solutions, caused by the square root in eq. (11), the outlet control-signal $u_{\text {Out }}$ will change to a value proportional to the inlet controlsignal $u_{I n}$. The proportional factor depends on the behaviour of the meter-in and meter-out control edge. To prevent cavitation in the inlet chamber, an additional pressure control will reduce the outlet control edge percentile to the calculated, see fig. 10. This control forces the system to be always in a passive load status. It is comparable to a load control valve.

$$
\begin{array}{r}
A_{C E, \text { Out }}=\pi \cdot d_{\text {Spool }} \cdot y_{\text {Out }} \\
y_{\text {Out }}=K \cdot \frac{\alpha \cdot Q_{\text {In,ref }}}{\alpha_{D} \cdot \sqrt{\frac{2}{\rho}} \cdot \pi \cdot d_{\text {Spool }} \cdot \sqrt{\Delta p}}
\end{array}
$$

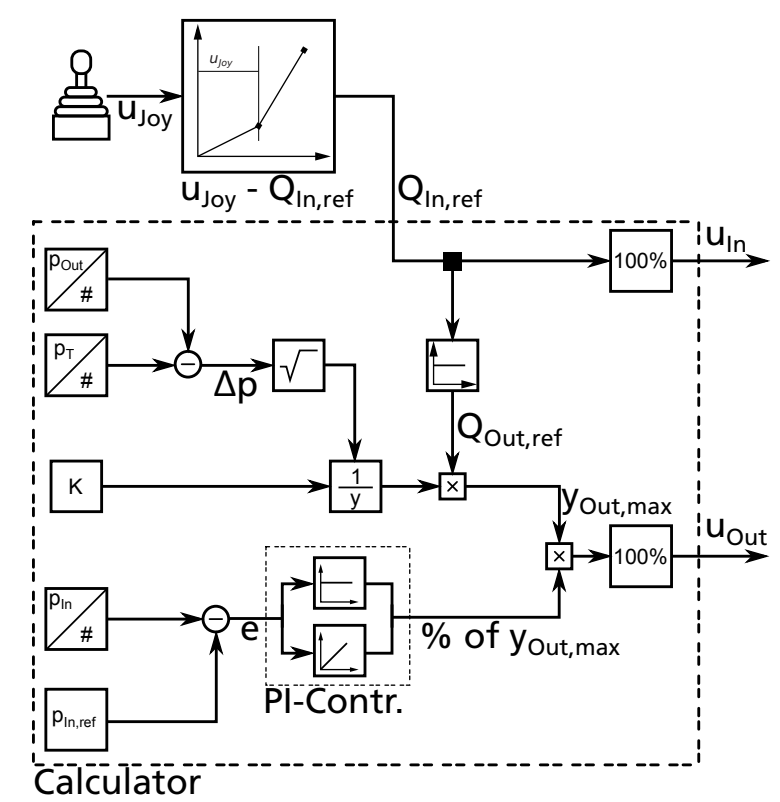

Figure 10: Pressure control of the inlet chamber 
Only in active load situations the EOM and the RcOM are used. In both OMs, the inlet chamber is completely connected to the tank, so the actuator has the ability to pull oil from the tank line with less losses as possible. In EOM, the actuator can also use the outlet flow rate, which reduces the required flow rate from the tank. During the retraction of a differential cylinder, the outlet flow rate is higher than the inlet flow rate, thus no oil from the tank is needed. The position of the outlet control edge is also calculated with eq. (11). While in EOM $\Delta p$ is the pressure difference between the outlet chamber and the tank line, in $\mathrm{RcOM} \Delta p$ is the pressure difference between the outlet chamber and the accumulator, including all other pressure losses, cf. eq. (8).

\section{Simulation}

The controller design is tested in a co-simulation model first for only one actuator, later for the hydraulic circuit of a mobile forestry crane. Both hydraulic circuits are built up in the simulation software DSHplus. The controller design and the virtual operator are built up in Matlab/Simulink. The section valve is represented by several orifices, which directly acts by the spool position. The spool position is calculated by the controller design without considering any valve dynamics. The influences of pipes, current losses and others are partially considered. The pump is driven by a constant speed. The load cycle for the mobile forestry crane is given by [2], cf fig. 18 . In the following subsection, the results of the single-actuator systems will be discussed explicitly.

\subsection{Load Cycles for the Single-Actuator System}

Several tests are needed to investigate the usability of the controller design. Here a differential cylinder is used as a singleactuator, cf. fig. 6 actuator two. The cylinder will extend and retract under several load conditions. A virtual operator (VO), which is represented by a closed-loop control of the pistons' position, is used to operate the cylinder. Therefore, it is possible to examine the operation commands, which will show the suitability in use. The VO is implemented according to [14]. The errors of the piston's position will be calculated with eq. (12). $x_{r e f}$ is the reference position and $x_{t c}$ represents the actual position related to the different test cycles

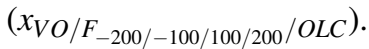

$$
\Delta x_{\text {max }, \text { ref }}=\frac{\max \left(\left|x_{\text {ref }}-x_{t c}\right|\right)}{\max \left(x_{r e f}\right)}
$$

To create a reference cycle, the movement of the cylinder was simulated by an open-loop control of the system. Therefore, a constant operation signal $u_{J o y, r e f}$ is used and no load is applied to the cylinder. $u_{\text {Joy,ref }}$ and the resulting movement $x_{\text {ref }}$ are shown in fig. 11. This movement is used as a reference path for the VO, which tries to follow the path under different loading conditions. As shown in fig. 11, the VO induces a delayed operation signal $u_{J o y, V O}$ causing a displaced movement of the cylinder.

The maximum absolute error appears for the maximum of $u_{\text {Joy }}=100 \%$ in amount of $\Delta x_{\max , 100}=6,2 \%$. For $u_{J o y}=$
$60 \%$ the absolute error between the nominal path and the controlled path is $\Delta x_{\max , 60}=4,6 \%$. The smallest error is caused by an operation signal of $u_{J o y}=30 \%$ in amount of $\Delta x_{\max , 30}=3,2 \%$.
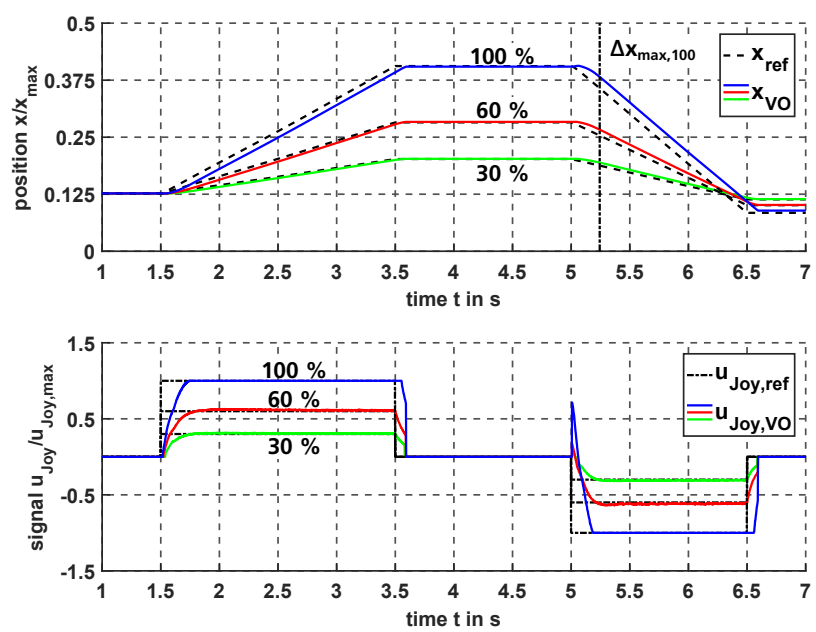

Figure 11: Piston's position $x_{\text {ref }}$ as the result of an open-loop control of $u_{J o y, r e f}$ and the position $x_{V O}$ as the result of the closed-loop control represented by the virtual operator signal $u_{\text {Joy }, V O}$

An overview of the different load conditions is given in fig. 12. Test cycle 2 shows the behaviour of the cylinder for different constant loads $( \pm 100 \mathrm{kN}, \pm 200 \mathrm{kN})$ during the whole test cycle. This represents for example the boom cylinder of a crane.

Test cycle 3 represents a load, which changes its direction abruptly during extension and retraction. During extension, the load changes from pulling to pushing ( $-200 \mathrm{kN}$ to $200 \mathrm{kN}$ ), for retraction vice versa. The duration of the load change amounts to $\Delta t_{\text {Change }}=0,2 \mathrm{~s}$. This load situation can be found in similar manner e.g. at the gripper or the stick cylinder of a crane.

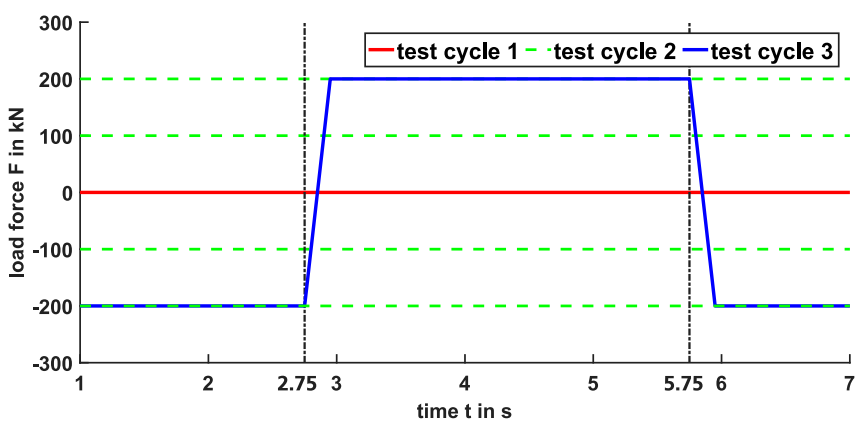

Figure 12: Load cycles for the single-actuator system

\subsection{Discussion of the Single-Actuator System}

To discuss the different load cycles, the author describes the cylinders movement, the control-signals, the behaviour of pressure and flow rate and the opening positions of the section valve's control edges. 


\subsubsection{Test Cycle 2}

The results of test cycle 2 indicate that the cylinders movement is influenced by an absolute error in amount of $\Delta x_{\text {max }, \text { ref }}=7,5 \%$ compared to the reference position $x_{\text {ref }}$, cf. fig. 13. Considering the maximum error of the VO $\Delta x_{\max , 60}$, the total absolute error is ca. $\Delta x_{\max , V O}=2,9 \%$, cf. eq. (13).

$$
\Delta x_{\max , V O}=\Delta x_{\max , r e f}-\Delta x_{\max , 60}
$$

The operation signals for a constant load of $F=100 \mathrm{kN}$ and $F=200 \mathrm{kN}$ show a distinctive amplitude at the beginning of the extension at $t \approx 1,5 \mathrm{~s}$, cf. fig. 13. This is caused by the structure of the VO, which tries to minimize the gap between the current pistons' position $x_{F 200 / F 100}$ and the nominal position $x_{\text {ref }}$. This gap results from the initial conditions of the simulation and has been neglected for this research. This leads to an acceptable suitability in use for actuators charged by constant loads.
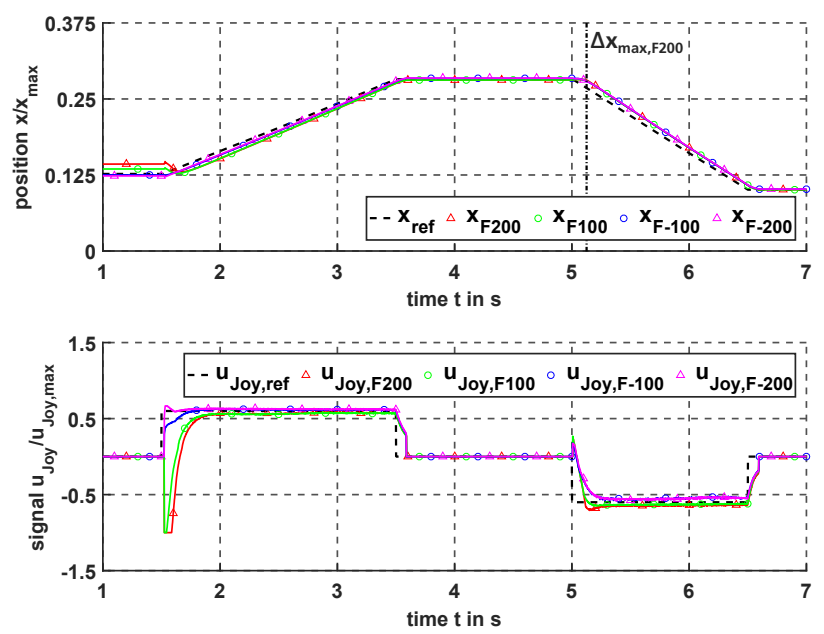

Figure 13: Piston's position of test cycle 2 and the operation signals of the VO for the different load cases; $u_{J o y, r e f}=60 \%$

The system pressure $p_{S y s}$ only rises, when the pump is connected to the actuator, cf. $t=1,5 s$ to $3,5 s$ in fig. 14 . The reason for the rising pressure at $t=5 \mathrm{~s}$ can be found in the mode switch of the controller design. In nominal position the $\mathrm{OM}$ of the system is the NOM, cf. status II in fig. 14. By adjusting $u_{J o y}$, at first the pump is connected to the actuator for a short duration until the control-signals for the EOM are released and the pressure drops. This time is long enough to transfer the pressure from the section valve to the pump.

One critical problem of the system is cavitation during the EOM, here during retraction. One possible way to solve this problem is adjusting the PI-controller of the pressure control, cf. section 2.2.1. Further criteria to activate EOM can help to reduce cavitation too. For example, the flow rate demanded by an actuator can be compared with the sum of the backflowing oil of other simultaneously operated actuators. If no oil is available, the EOM will not be activated. Furthermore, a by-pass from the tank to the necessary actuator, can avoid high pressure losses on the line.
Fig. 14 also shows the flow rate of the pump and of the control edges of the section valve. $Q_{P A}$ and $Q_{P B}$ are the flow rate from the pump to the cylinder chambers A and B. $Q_{A T}$ and $Q_{B T}$ are the flow rate from the actuator to the tank line. During extension, status (I), the pump supports the actuator and the pressure in the outlet chamber manners $p_{\text {Out }}=2 \%$ of $p_{\max }$. During retraction, the pump is not used any more and the required flow rate of the actuator will be supplied by the tank-line.

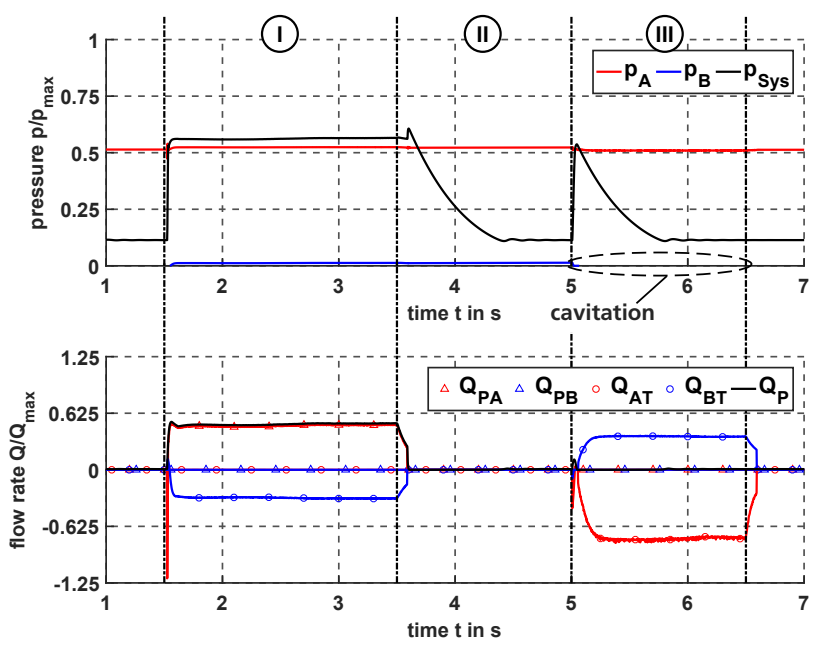

Figure 14: Pressure of the system and the cylinders' chambers $A$ and $B$ in test cycle $2(F=200 k N)$, cf. 3; flow rate of the pump and the control edge of the section valve; $P A / B$ pump to chamber $A / B, A / B T$ - chamber $A / B$ to tank line

\subsubsection{Test Cycle 3}

Test cycle 3 is operated in a closed-loop control (CLC) by the $\mathrm{VO}$ as well as in an open-loop control (OLC) for a given operation signal $u_{\text {Joy }}=60 \%$. This test shows the behaviour of the system, when the operator does not adapt to changing loads. It also shows the ability of the operator to stabilize the system. While in OLC, the piston drifts away, $x_{O L C}$, and causes an error of $\Delta x_{\max , O L C}=12 \%$ to the reference path $x_{\text {ref }}$, the VO can stop this drifting by its fast, but short reaction, $u_{J o y, V O}$ and control the system into the new OM, cf. fig. 15. So the maximum error can be reduced to $\Delta x_{\max , V O}=5 \%$. Compared to test cycle 2 , the operator only has to stop for a short time or, in this test cycle, the operator has to expect a step of the piston from about $\Delta x_{\text {step }}=3 \%$ with respect to the maximum extension of the cylinder $x_{\max }$. The amount of the step generally depends on the current operation signal $u_{J o y}$ and the magnitude of the load change.

Figure 16 shows the pressure and the flow rate during test cycle 3, controlled by the VO. The pressure in the actuators' chambers changes with the magnitude of the load. When the load swaps from pulling to pushing the pressures in chamber $\mathrm{A}$ and $\mathrm{B}$ are equal. Then the piston accelerates because of the active load situation and the VO reacts by an operation signal into the opposite direction, cf. fig. 15 at $t \approx 2,8 s$. This entails that the actuators status for the controller design changes to passive load and the pump is connected to cham- 

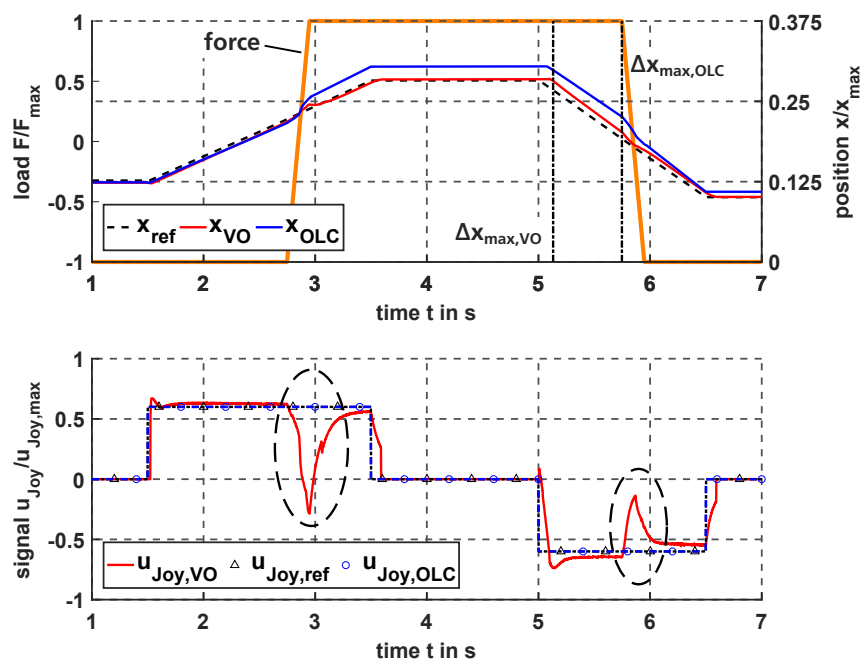

Figure 15: Piston's position of test cycle 3 and the operation signals of the $V O$ and accordingly of the OLC for the different load cases

ber $\mathrm{B}$, what causes an increasing pressure in that chamber, $\mathrm{cf}$. fig. 16 at $t \approx 2,8 s$. So the force is held by the section valve and can now be controlled by the meter-out orifice to the accumulator, which is not shown in the diagrams. In fig. 16 it is recognizable, that orifice AT has a positive flow rate and thus in-flowing oil. Out-flowing oil is not mentioned, because in this moment, the oil flows into the accumulator.

The problem of cavitation still remains during the EOM, which is one point to be focused on in the further research.

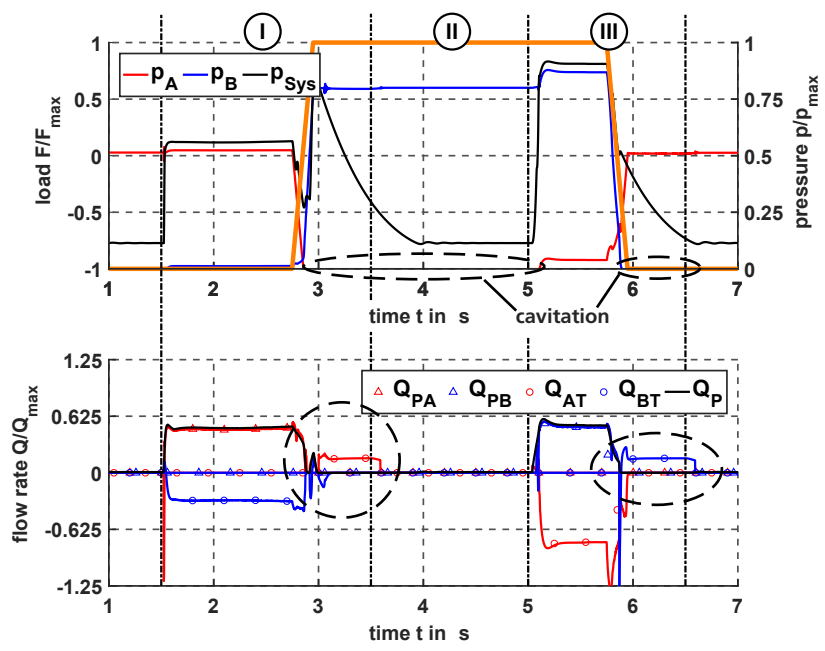

Figure 16: Pressure of the system and the cylinders' chambers $A$ and $B$ in test cycle 3, cf. fig. 3; flow rate of the pump and the actuator; system is controlled by the VO; $P A / B$ - pump to chamber $A / B, A / B T$ - chamber $A / B$ to tank line

A look to the upper diagram of fig. 17 shows the opening position $y_{P A / P B / A T / B T}$ of the control edges for test cycle 3 operated by the OLC. When the load changes its direction, the mode switch of the controller design swaps the operation signals from NOM to EOM. The valve controlling chamber A changes from the pump to a fully opened connection to the tank. The valve for chamber B also opens to the tank, but with the position calculated according to sec. 2.2.1. The lower diagram of fig. 17 shows the opening position of the control edges operated by the VO.

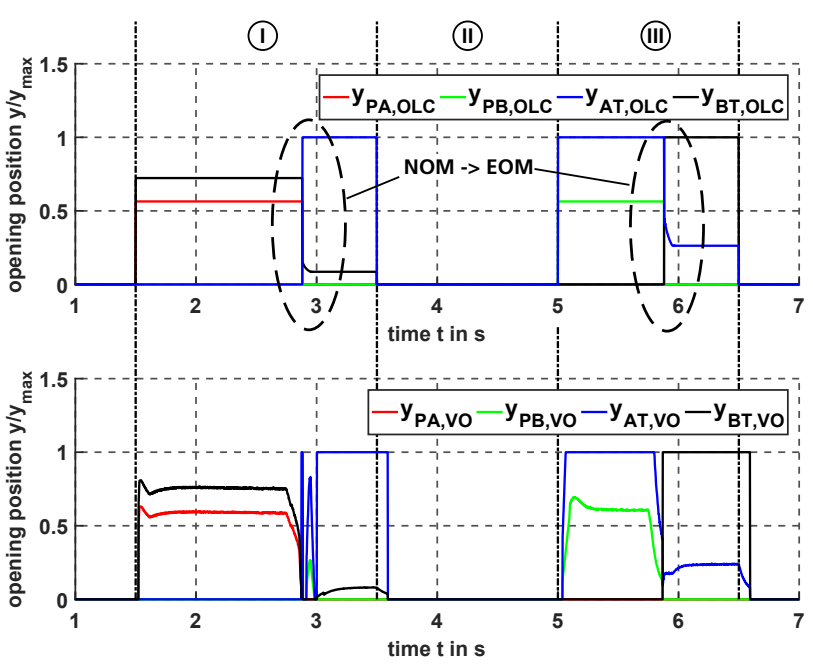

Figure 17: Opening of the section valves control edges due to the signals of the controller design during the load change. $O C$ - open-loop control, VO - virtual operator; $P A / B$ - pump to chamber $A / B, A / B T$ - chamber $A / B$ to tank line

\subsection{Potential for the Mobile Forestry Crane}

The controller design is implemented in a simulation model of an hydraulic circuit consisting of three actuators. The first actuator is a boom cylinder, the second represents a group of slewing cylinders and the last one is a rotation unit of the gripper. Each actuator is actuated by the same adjustment of the virtual operator (VO), who tries to follow the given positions, cf. fig. 18. Simultaneously, a given load is applied on the actuators. Thus, this simulation represents a typical load cycle of a mobile forestry crane. The actuators positions and the given loads are shown in fig. 18. The data were measured and defined by Scherer [2].

The red deposited surfaces show the potential periods for the boom cylinder to be controlled by EOM or RcOM during the load duty cycle.

Four different kinds of systems are shown in fig. 19. The first system is the normal electro-hydraulic flow-on-demand system with conventional valves. This system acts as the reference one. For the second system, the conventional valves are replaced by separated control edges. In the controller design only the normal operation mode (NOM) with a pressure controlled inlet chamber is implemented. The third system uses the energy neutral mode (EOM) to disconnect the pump during active loads. This mode is only implemented for the boom cylinder, because this actuator is most suitable for the EOM. The last system includes an hydraulic accumulator, so the system becomes a hybrid system with the possibility to recuperate energy.

For every system, the used hydraulic energy $E_{H y d r}$ of the pump is calculated by eq. 15. The energy stored in the ac- 


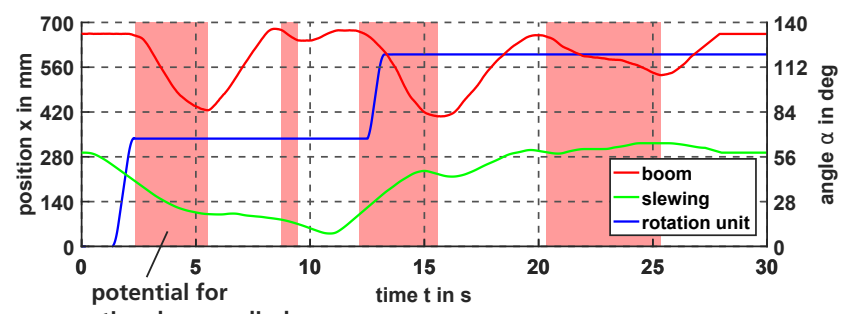

recuperation, boom cylinder

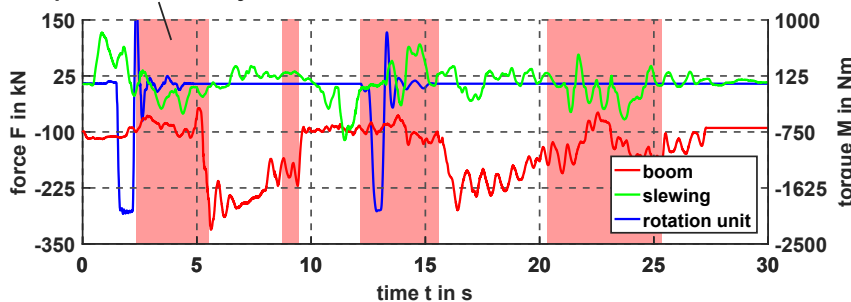

Figure 18: Load duty cycle of a mobile forestry crane; actuator movements and loads [2]

cumulator is calculated equally by using the pressure of the accumulator and the flow rate into it.

$$
\begin{aligned}
P_{H y d r} & =\Delta p_{S y s} \cdot Q_{P} \\
E_{H y d r} & =\int P_{H y d r} d t
\end{aligned}
$$

The energy demand of the pump during one duty cycle sums up to $E_{H y d r}=353 \mathrm{~kJ}$ for the first system. Compared to the second system, the energy saving potential is $0.85 \%$. With the introduction of the EOM in this application, it is possible to reduce the energy demand up to $18.7 \%$. Introducing the hydraulic accumulator and the RcOM, the energy demand of the pump is nearly the same as of the third system. However, now it is possible to use recuperated energy of app. $8.8 \%$ of the energy demand of the pump.

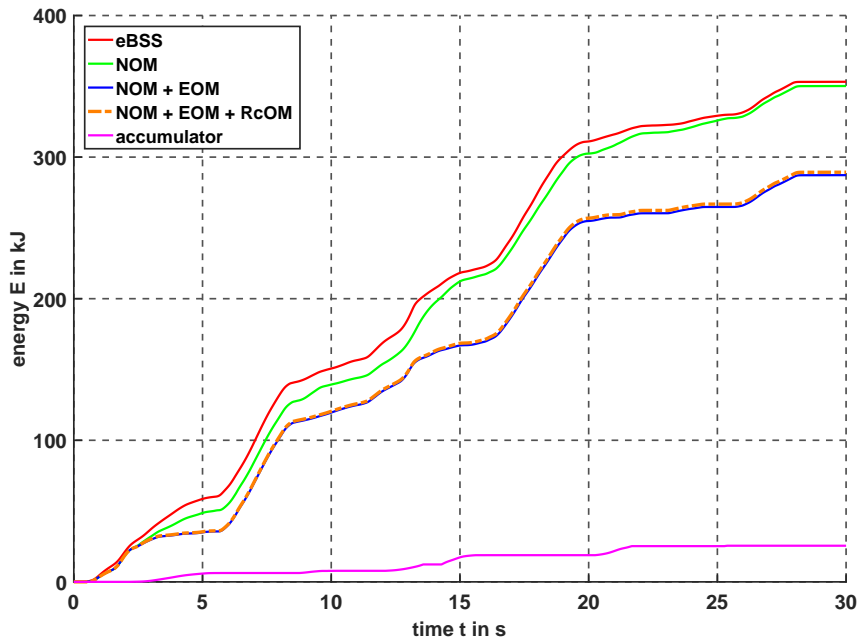

Figure 19: Energy demand of the pump for different systems

\section{Outlook}

During preparation of this paper, the installation of the test bench is still in progress, so the first results are expected for autumn 2017. On the test bench, the calculated values in section 2.2 will be used as an orientation to generate the actuation signals via look-up tables. This will allow a safe controlling of the actuators without measuring the flow rate. Building up the test bench will give more information about problems and operating feedback.

In a last step the tested and evaluated system will be implemented in a prototype to achieve information about the effort and influences on the forestry crane.

\section{Acknowledgements}

These perceptions are based on a research project funded by the Deutsche Bundesstiftung Umwelt (DBU) and our partner Weiss Mobiltechnik GmbH. Furthermore special thanks goes to FLUIDON GmbH providing the simulation software DSHplus free of charge.

\begin{tabular}{|c|c|c|}
\hline Designation & Denotation & Unit \\
\hline EOM & energy neutral operation mode & - \\
\hline eBSS & $\begin{array}{l}\text { electro-hydraulic } \quad \text { flow-on- } \\
\text { demand system }\end{array}$ & - \\
\hline IM & independent metering & - \\
\hline $\mathrm{LS}$ & load sensing & - \\
\hline NOM & normal operation mode & - \\
\hline $\mathrm{OM}$ & operation mode & - \\
\hline OLC & open-loop control & - \\
\hline $\mathrm{RgOM}$ & regeneration op. mode & - \\
\hline $\mathrm{RcOM}$ & recuperation op. mode & - \\
\hline VO & virtual operator & - \\
\hline$\alpha$ & surface ratio & - \\
\hline$\alpha_{D}$ & flow coefficient & - \\
\hline$\rho$ & density of oil & {$\left[\mathrm{kg} / \mathrm{m}^{3}\right]$} \\
\hline$A_{A / B}$ & surface chamber $A$ or $B$ & {$\left[\mathrm{~m}^{3}\right]$} \\
\hline$A_{C E, \text { Out }}$ & flow surface control edge & {$\left[\mathrm{m}^{3}\right]$} \\
\hline$A_{\text {In }}$ & surface inlet chamber & {$\left[\mathrm{m}^{3}\right]$} \\
\hline$A_{\text {Out }}$ & surface outlet chamber & {$\left[\mathrm{m}^{3}\right]$} \\
\hline$E_{H y d r}$ & hydraulic energy & {$[\mathrm{J}]$} \\
\hline$F_{\text {Load }}$ & resulting load force & {$[\mathrm{N}]$} \\
\hline$K$ & constant & - \\
\hline$Q$ & flow rate & {$[1 / \mathrm{min}]$} \\
\hline$Q_{A c c}$ & flow rate to accumulator & {$[1 / \mathrm{min}]$} \\
\hline$Q_{I n}$ & inlet flow rate & {$[1 / \mathrm{min}]$} \\
\hline$Q_{\text {In,ref }}$ & ideal inlet flow rate & {$[1 / \mathrm{min}]$} \\
\hline$Q_{\text {Out }}$ & outlet flow rate & {$[1 / \mathrm{min}]$} \\
\hline$Q_{\text {Out }, \text { ref }}$ & ideal outlet flow rate & {$[1 / \mathrm{min}]$} \\
\hline$Q_{\text {Pump }, \text { NOM }}$ & flow rate in NOM & {$[1 / \mathrm{min}]$} \\
\hline$Q_{\text {Pump }, \text { RgOM }}$ & flow rate in $\mathrm{RgOM}$ & {$[1 / \mathrm{min}]$} \\
\hline$Q_{\text {Pump }, E O M / R c O M}$ & flow rate in EOM or RcOM & {$[1 / \mathrm{min}]$} \\
\hline$Q_{\text {Tank }}$ & flow rate to the tank & {$[1 / \mathrm{min}]$} \\
\hline$P_{H y d r}$ & hydraulic power & {$[\mathrm{W}]$} \\
\hline
\end{tabular}

\section{Nomenclature}




\begin{tabular}{lll}
\hline Designation & Denotation & Unit \\
\hline$d_{\text {Spool }}$ & diameter of valve spool & {$[\mathrm{m}]$} \\
$\Delta p$ & pressure difference & {$[\mathrm{bar}]$} \\
$\Delta p_{\text {Losses }}$ & pressure losses & {$[\mathrm{bar}]$} \\
$\Delta p_{Q, A c c}$ & pressure for full opened valve & {$[\mathrm{bar}]$} \\
$\Delta p_{\text {RcOM }, \text { on }}$ & upper limit for RcOM & {$[\mathrm{bar}]$} \\
$p_{A / B}$ & pressure chamber A or B & {$[\mathrm{bar}]$} \\
$p_{\text {Acc }}$ & pressure of accumulator & {$[\mathrm{bar}]$} \\
$p_{\text {EOM,on }}$ & upper limit for EOM & {$[\mathrm{bar}]$} \\
$p_{\text {Out }}$ & pressure outlet chamber & {$[\mathrm{bar}]$} \\
$p_{T}$ & pressure tank & {$[\mathrm{bar}]$} \\
$p_{\text {Sys }}$ & system pressure & {$[\mathrm{bar}]$} \\
$\Delta t_{\text {Change }}$ & duration of load change & {$[\mathrm{s}]$} \\
$t_{1}$ & moment of mode switch & {$[\mathrm{s}]$} \\
$u$ & several control-signals & {$[-]$} \\
$u_{\text {In/Out }}$ & control-signals to section valve & {$[-]$} \\
$u_{\text {Joy, }, \ldots}$ & operation signal & {$[-]$} \\
$u_{\text {Pump }}$ & operation signal of the pump & {$[-]$} \\
$y$ & valve spool position & {$[\mathrm{m}]$} \\
$y_{\text {Out }}$ & outlet valve spool position & {$[\mathrm{m}]$} \\
$y_{\text {PA/PB/AT } / B T}$ & opening position of control edge & {$[-]$} \\
$\Delta x_{\text {max }}$ & several maximum errors & {$[-]$} \\
$\Delta x_{\text {step }}$ & error by load change & {$[-]$} \\
$x_{\text {ref }}$ & reference position & {$[\mathrm{m}]$} \\
$x_{\text {tc }}$ & position in test cycle & {$[\mathrm{m}]$} \\
\hline & &
\end{tabular}

\section{References}

[1] Shelley Nation and Aaron Jagoda. Smart Machines. ivt International Off-Highway 2017, pages 72-74, 2017.

[2] Martin Scherer. Beitrag zur Effizienzsteigerung mobiler Arbeitsmaschinen: Entwicklung einer elektrohydraulischen Bedarfsstromsteuerung mit aufgeprägtem Volumenstrom. PhD thesis, Karlsruhe, 2015. Zugl.: Karlsruhe, KIT, Diss., 2015.

[3] Dieter Will. Hydraulik : Grundlagen, Komponenten, Schaltungen. SpringerLink : Bücher. Springer Berlin Heidelberg, 2011.

[4] M. Axin. Fluid Power Systems for Mobile Applications with a Focus on Energy Efficiency and Dynamic Characteristics. PhD thesis, Linköping University, Linköping, Sweden, 2013.

[5] A. Sitte and J. Weber. Structural design of independent metering control systems. pages 261-270. Proceedings of the 13 th Scandinavian International Conference on Fluid Power, Linköping, Sweden 2013.

[6] Ruqi Ding, Bing Xu, Junhui Zhang, and Min Cheng. Bumpless mode switch of independent metering fluid power system for mobile machinery. In Automation in Construction 68, pages 52-64. 2016.

[7] P. Nagel. Entwicklung einer Betriebsstrategie zur Energierückgewinnung in hybriden Mehrverbrauchersystemen. PhD thesis, Karlsruhe, 2016.
[8] P. Thiebes. Hybridantriebe für mobile Arbeitsmaschinen: grundlegende Erkenntnisse und Zusammenhänge, Vorstellung einer Methodik zur Unterstützung des Entwicklungsprozesses und deren Validierung am Beispiel einer Forstmaschine. PhD thesis, Karlsruhe, 2012. Zugl.: Karlsruhe, KIT, Diss., 2011.

[9] Jan Siebert and Marcus Geimer. Entwicklung eines effizienzgesteigerten Load-Sensing-Systems für mobile Arbeitsmaschinen durch Reduzierung systembedingter Druckverluste. In 9. Kolloquium Mobilhydraulik : Karlsruhe, 22./23. September 2016, pages 11-27. KIT Scientific Publishing, Karlsruhe, sep 2016.

[10] Dietmar Findeisen. Ölhydraulik : Handbuch für die hydrostatische Leistungsübertragung in der Fluidtechnik. VDI-[Buch]. Springer, Berlin, 5., neu bearb. aufl. edition, 2006.

[11] Wolfgang Backé, Gerd-Dieter Wobben, and Elmar Wassenberg. Untersuchungen des stationären und dynamischen Verhaltens mechanisch und elektrisch vorgesteuerter Druckbegrenzungsventile. Forschungsberichte des Landes Nordrhein-Westfalen ; 2811 : Fachgruppe Maschinenbau, Verfahrenstechnik. Westdt. Verl., Opladen, 1979.

[12] Wolfgang Backé, Nicolae Hamburger, and Hans-Peter Riedel. Untersuchungen über das dynamische Verhalten von Stromregelventilen. Forschungsberichte des Landes Nordrhein-Westfalen ; 2435. Westdt. Verl., Opladen, 1974.

[13] Zhiming Wu. Einbindung einer hydraulischen Rekuperationseinheit in ein elektr.-hydr. Bedarfsstromsystems mit getrennten Steuerkanten. Master's thesis, Karlsruhe Instiute of Technology - KIT, January 2017.

[14] P. Thiebes and T. Vollmer. Modellierung des Fahrers zur Untersuchung von Antriebssträngen in der 1DSimulation am Beispiel eines Radladers mit Hybridantrieb. In Tagungsband zur 3. Fachtagung Hybridantriebe für mobile Arbeitsmaschinen, pages 47-59, Karlsruhe, 2011. 